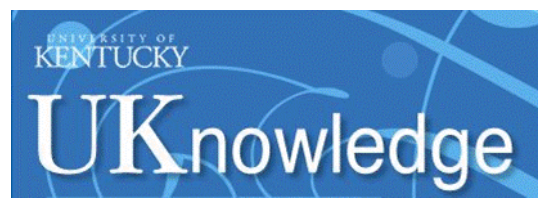

University of Kentucky

UKnowledge

$9-2009$

\title{
Sexuality and Persons with Down Syndrome. A Study from Brazil
}

\author{
Bruna Marques Bononi \\ Faculty of Medical Sciences Santa Casa, Brazil \\ Maria José Carvalho Sant'Anna \\ Faculty of Medical Sciences Santa Casa, Brazil \\ André Chao Vasconcellos de Oliveira \\ Faculty of Medical Sciences Santa Casa, Brazil \\ Tadeu Silveira Renattini \\ Faculty of Medical Sciences Santa Casa, Brazil \\ Carla Franchi Pinto \\ Faculty of Medical Sciences Santa Casa, Brazil
}

See next page for additional authors

Follow this and additional works at: https://uknowledge.uky.edu/pediatrics_facpub

Part of the Gender and Sexuality Commons, and the Pediatrics Commons

Right click to open a feedback form in a new tab to let us know how this document benefits you.

\section{Repository Citation}

Bononi, Bruna Marques; Sant'Anna, Maria José Carvalho; de Oliveira, André Chao Vasconcellos; Renattini, Tadeu Silveira; Pinto, Carla Franchi; Passarelli, Maria Lúcia; Coates, Verônica; and Omar, Hatim A., "Sexuality and Persons with Down Syndrome. A Study from Brazil" (2009). Pediatrics Faculty Publications. 76.

https://uknowledge.uky.edu/pediatrics_facpub/76

This Article is brought to you for free and open access by the Pediatrics at UKnowledge. It has been accepted for inclusion in Pediatrics Faculty Publications by an authorized administrator of UKnowledge. For more information, please contact UKnowledge@lsv.uky.edu. 
Sexuality and Persons with Down Syndrome. A Study from Brazil

Digital Object Identifier (DOI)

https://doi.org/10.1515/IJAMH.2009.21.3.319

Notes/Citation Information

Published in International Journal of Adolescent Medicine and Health, v. 21, no. 3, p. 319-326.

(c) Freund Publishing House limited

The copyright holder has granted permission for posting the article.

Reprinted as a book chapter in Adolescence and Chronic IIIness. A Public Health Concern. Hatim Omar, Donald E. Greydanus, Dilip R. Patel, \& Joav Merrick, (Eds.). p. 283-290.

\section{Authors}

Bruna Marques Bononi, Maria José Carvalho Sant'Anna, André Chao Vasconcellos de Oliveira, Tadeu Silveira Renattini, Carla Franchi Pinto, Maria Lúcia Passarelli, Verônica Coates, and Hatim A. Omar 


\section{Sexuality and persons with Down syndrome. A study from Brazil}

Bruna Marques Bononi, MD', Maria José Carvalho Sant'Anna, $\mathrm{MD}^{1}$, André Chao Vasconcellos de Oliveira, MD', Tadeu Silveira Renattini, $\mathrm{MD}^{1}$, Carla Franchi Pinto, $\mathrm{MD}^{2}$, Maria Lúcia Passarelli, $\mathrm{MD}^{2}$, Veronica Coates, $\mathrm{MD}^{1}$ and Hatim $\mathrm{A}$ Omar, $\mathrm{MD}^{3}$

'Adolescent Clinical Unit and 'Department of Pediatrics, Santa Casa de São Paulo, Faculty of Aredical Sciences, São Paulo, Brazili; ${ }^{3}$ Division of Adolescent Medicine, Department of Pediatrics, University of Kentucky, Lexington, Kentucky, United States of America

Abstract: In recent years, important gains and changes have been observed in the life of teenagers with Down syndrome (DS) with increased inclusion into society. This review will discuss adolescence and sexuality in teenagers with DS from a descriptive study of 50 patients with DS between the ages of 10 and 20 years. The mean age was 13.5 years, $50 \%$ females; $86 \%$ went to school with $62.2 \%$ in school for over six years. Of the patients that attended school, $60 \%$ went to special education school and only $10 \%$ read and wrote correctly. In an evaluation of autonomy, $66 \%$ took showers, $78 \%$ performed their physiological needs, $77 \%$ intimate hygiene and $76 \%$ oral hygiene without help. $42 \%$ affirmed being able to do anything that is asked; $22 \%$ perform all tasks in the home: $10 \%$ felt they were incapable of doing anything and $4 \%$ used public transportation without help. $42 \%$ of the teenagers masturbated, $24 \%$ on a daily basis, $75 \%$ in private, and $25 \%$ in a public location. $42 \%$ had already kissed at a mean age of 12.9 years, mean age of the partner 16.1 years; $268 \%$ of these partners had DS. $82 \%$ found themselves attractive and $33 \%$ would not change anything in their appearance. We found that they presented normal development in the exercise of their sexuality, but with important difficulties in their autonomy and difficulties in school, needing careful interventions to make their social interaction the best possible. Their pubertal development was normal and they were satisfied with their body image with future perspectives of working, finding a partner, and living a normal life of getting married and having children.

Komords: Down syndrome, sexuality, human development, Brazil

Correxpondence: Maria José Carvalho Sant'Anna, MD, Rua Nuno Pinto 46, Jardim São Paulo, CEP02045-030, São Paulo City, Brazil. Tel: (55+11) 69502508; Fax: (55+11) 69541577; E-mail: mjcsantanna@gmail.com

Submimed: October 15, 2008. Revised: December 11, 2008. Accepted: December 20, 2008."

\section{INTRODUCTION}

Teenagers with Down Syndrome (DS) must be prepared for a life of limitations and possibilities. Important gains and changes have been, observed in relation to such individuals, and society in general is increasingly accepting and allowing their inclusion into community roles. The public is tending to see this deficiency as a natural diversity within humanity, and with the advancement of the treatments devoted to chronic illnesses, life expectancy has greatly increased. Health professionals are now confronted with a new reality to provide health services for teenagers with DS and the challenge of adapting to their needs. 
As the care to special needs of these adolescents with intellectual disability improves, their quality of life improves as well, and at the same time that integration within a community structure offers great advantages, it should not be forgotten that there are also more risks, liberties and responsibilities. Therefore, during childhood and especially adolescence, it is necessary that they develop self-awareness, the ability to choose, criticize, and stimulate their own autonomy, to prepare for work, questions and acts about sexuality.

It is essential to remember that sexual desire is ever present, independent of the degree of mental/intellectual impairment. This discussion is usually handled with prejudice and discrimination, especially when dealing with patients with DS, causing various controversies. These young adults present a variety of manifestations in relation to sexuality and reproductive health, reflecting their stage of development, their experiences and circumstances of their lives. Masters and Johnson (1) also discussed the importance of recognizing that individuals with mental deficiencies differ in their ability in learning, independence, emotional stability, and social abilities.

It is in this context of fear and uncertainties that healthcare providers (HCP) can help the teenager to develop. Often, the family is unable to answer all the questions posed by these individuals, offering answers that are often incomplete or wrong. Therefore HCP should assume the role of counselor and friend, providing the necessary advice and guidance to his/her parents.

In this particular group, questions regarding sexuality (including pregnancy and contraception) are often overlooked. Several studies have demonstrated that in severely compromised patients, where social exile and negative self-image makes sexuality difficult, their actual sexuality is not different from common individuals. Sexuality is always present and may be expressed in its affective component (the feeling of good will), erotic (desire, excitement and pleasure) or affective-erotic (the association that provides a more genuine relationship).

The title of 'mentally deficient', almost entirely used indiscriminately, masks the differences and peculiarities of each case. Despite differences in their learning capacity, independence, social stability, and outlook on sexuality, almost all are able to understand some level of sexual knowledge and social behavior. The more compromised DS individuals have problems that are centered more in questions of hygiene and self-care, making it necessary most of the time, for example, to reduce or prevent menstrual flow.

Many beliefs and taboos still remain in relation to the mentally challenged, ranging from being asexual to overly sexual. Thus, such individuals are often times treated as if they were children. Most families assume an overprotective role, seeing and caring for these individuals as if they were infants and asexual. For the teenager with some type of mental limitation, the expected and progressive independence from their parents is delayed or even absent. Therefore, it is necessary that the process of transferring responsibilities should have its own rhythm for each teenager, for each family, and for each limitation, with an emphasis on communication and encouraging the teen to occupy his place within society. It is up to the health professional working with these patients to assist them, as well as their families, in the process of reaching a maximum degree of independence. Family members, HCP, and teachers sometimes underestimate the abilities of such individuals, believing that they will never become sexually active. 
Mental deficiency alone does not determine sexual behavior. Despite the social isolation that many teenagers with DS face, studies have shown that many of these teens would like to have a sexual life, get married, and have children. Such teenagers have fewer opportunities to live with their peers, making it difficult to achieve their life goals. The probability of these individuals becoming isolated from society is high, in turn leading to difficulty or inability to find partners. 'Different' adolescents are excluded or may feel excluded, therefore, as a way to overcome these differences and barriers, they may assume behaviors that could be of risk, each time greater, such as sexual activity without being prepared or with insufficient protection or even nonconsensual. For such a teenager, sexual relations may signify being attractive, loved, chosen, even if affection is not involved.

The health professional should assist theses young adults and approach their questions in a clear and objective manner, providing the conditions for the exercise of a healthy and safe sexual life. In addition to understanding the sexual possibilities, discussions, and orientations for the challenged patient and their family in relation to sexuality, the HCP should also point out the vulnerabilities of these patients (in light of their diminished capacity of self protection, victims of sexual abuse). From childhood, such individuals should understand healthy attitudes that should be taken in relation to their bodies. If integration within the community is offered, the DS adolescent will need orientation regarding abilities and appropriate attitudes of social behavior. It is necessary to emphasize the importance of shedding light on sexuality and contraceptive measures for these teens, their parents, and their educators in an individualized fashion or through educational programs (2).

The information regarding sexuality should include relationships with others in a social context, information about differences between genders, physiological and psychological understanding about sexual development, and orientation regarding adequate social behavior. According to Elkins and Haefner (3), conversation concerning normal physical development and how to avoid sexual abuse should always be approached. Blum (4) argued that when caring for the mentally challenged, it is of utmost importance that instructions be provided about hygiene, menstruation, masturbation, sexually transmitted diseases (STDs) and AIDS, contraception, and marriage. This author also discussed (4) some common beliefs concerning mentally challenged teenagers that in time have been proven to be wrong, like the following statements:

- Teenagers with deficiencies are not sexually active

- The social and sexual aspirations of the teenager with deficiencies and chronic illnesses are different from that of their peers

- Parents of teenagers with deficiencies provide sufficient sexual education

- Teenagers with chronic illnesses are sexually vulnerable

- Problems in relation to sexual expression are because of chronic diseases

- Individuals with chronic diseases are not satisfied with their appearance.

One review (5) concluded that the pubertal development of individuals with DS is similar to that of other adolescents. Hormonal studies proved that the hormones responsible for sexual maturation of women with DS were equivalent to those of women in the general population, with the age of the first menstruation approximately 12.5 
Table 1. Autonomy in the daily activity

\begin{tabular}{|c|c|c|c|c|}
\hline & Shower & Physiological needs & Intimate hygiene & Oral hygiene \\
\hline & \multicolumn{4}{|c|}{ Percent } \\
\hline Autonomy & 66 & 66 & 78 & 76 \\
\hline With help & 24 & 24 & 12 & 14 \\
\hline Total dependence & 10 & 10 & 6 & 10 \\
\hline No answer & - & 4 & - & - \\
\hline
\end{tabular}

years and in normal women around 12.1 years. The authors also showed that women with DS have regular menstrual cycles.

Pueschel and Scola (6) questioned the parents of children with DS about their perception in relation to their children's social interactions, interest in the opposite sex, sexual function, and sexual education. The authors discovered that $40 \%$ of male teenagers and $22 \%$ of the female teenagers masturbated. Over half the $\therefore{ }^{\cdots}$ gers showed interest in the opposite sex and had social aspirations. Therefore, the $\mathrm{HCP}$ has a fundamental role because many times he/she is the only reference in the sexual orientation of this population, and because of this, it is necessary to create space within the medical consultation, where the HCP can approach and discuss aspects of sexuality, provide information about contraceptive measures, and alert the patient to the risks and prevention of STDs.

One of the fundamental aspects for developing social skills is helping teenagers understand, in full, their limitations. Awareness and acceptance of this syndrome may cause suffering to the teenager and their parents but are essential for the full development of their potential and the reformulation of their life goals given the limitations imposed.

\section{METHODS}

We conducted a cross-sectional study of 50 teenagers with Down Syndrome (DS) aged between 10 and 20 years, who attended the multi-professional DS clinic of the Department of Pediatrics of the Santa Casa de São Paulo during the period 1 May 2007 to 30 April 2008. The study was evaluated and approved by the institutional Ethics Committee on Humans. A structured questionnaire was applied by the researchers along with the teenager with DS after authorization by the adolescent and his/her caretaker, with both being informed about the goal and finality of this study with signed informed consent.

\section{RESULTS}

The age of the teenagers ranged from 10 to 20 years, with a mean of 13.5 years; $64 \%$ were younger than 14 years, $50 \%$ were of the male gender; $86 \%$ were enrolled in school and $62.2 \%$ were in school for over six years, $4.7 \%$ in an all day long setting. Of those who went to school, $73.3 \%$ were enrolled in public schools, $40 \%$ in traditional schools, and $60 \%$ in special education schools. $28 \%$ of the teenagers considered themselves alphabetized, with only $38 \%$ being able to write their names. $10 \%$ read and wrote correctly, and $6 \%$ read and wrote functionally. In analyzing the functionality of these teenagers, we found that most were able to function independently, see table 1 .

Of the 25 female teenagers evaluated, $26 \%$ had already menstruated, with a mean age of menarche 11.5 years. $18 \%$ knew the 
date of their last menstruation, the flow was regular in $66.6 \%$ and most $(56 \%)$ were responsible for their intimate hygiene.

Of all interviewed, $36 \%$ affirmed knowing what sexual desire was, and $50 \%$ described already having felt sexual desire. When questioned about masturbation, $18 \%$ described knowing what it is, and $42 \%$ answered that they frequently masturbated, with $24 \%$ doing so daily, $75 \%$ in private locations and $25 \%$ in public locations. Regarding kissing, $42 \%$ affirmed that they had already kissed, being that $85.7 \%$ were simple lip kisses. The mean age for the first kiss was at 12.9 years of age, and the mean age of the partner during this first kiss was 16.1 years. Of these partners $28.6 \%$ also had DS, and only two teenagers had kissed more than three partners. Of all interviewed, $18 \%$ had already dated, with one-third having had relationships with other DS patients.

One 18 year old female teenager had sexual relations with a 15 year old partner, yet did not respond as to whether or not he had any syndrome. $34 \%$ answered that they had been given education about sexuality and that the majority $(70 \%)$ were oriented by their parents. However, only $18 \%$ had discussed sexual issues with their parents and the same percentage said they discussed sex in school.

In relation to future goals of these teenagers, $58 \%$ said they intended to work, with $20.7 \%$ wanting to be teachers. When questioned about marriage, $56 \%$ showed interest and $52 \%$ intended to have children. Most subjects also showed good self-esteem, see table 2. A curious answer was given by a female teenager, saying that if she could, she would rather not have DS. Most patients were satisfied with themselves, see table 3 .

Of these teenagers, $82 \%$ demonstrated aptitude in helping with tasks in their home, with the most often performed tasks related
Table 2. Appearance

\begin{tabular}{lc}
\hline \multicolumn{1}{c}{ Response } & Percent \\
\hline Good looking & 82 \\
Bad looking & 2 \\
No answer & 16 \\
\hline
\end{tabular}

Table 3. What would you change about yourself?

\begin{tabular}{lc}
\hline \multicolumn{1}{c}{ Response } & Percent \\
\hline No answer & 43 \\
Nothing & 33 \\
Hair & 9 \\
Shoulder/arms & 4 \\
Stomach & 4 \\
Not aware & 2 \\
Foot & 2 \\
Having Down Syndrome & 2 \\
\hline
\end{tabular}

to dishes (washing, drying, putting them away) and with general cleaning (making the bed, putting away objects). On the other hand, $66 \%$ did not perform any activity outside their homes, $73 \%$ went to the grocery only for small purchases. $70 \%$ performed leisure activities-of these 57\% performed some sporting activity, $20 \%$ went to parks, and $20 \%$ went to the theater and movies. Of those who performed leisure activities, $43 \%$ were authorized and did so by themselves. The majority ( $88 \%)$ went to parties and social events. When openly questioned about what they felt capable of doing alone, $4 \%$ affirmed that they were able to do anything that is asked; $22 \%$ felt that they were capable of performing tasks of the home, $10 \%$ responded not being able to do anything, and $4 \%$ could use public transportation without help.

\section{DISCUSSION}

If adolescence is a period of challenges and confrontations for the teenager with normal 
cognitive abilities, these problems can be much greater for the teenager with DS. Teenagers with mental deficiencies live varying degrees of social isolation, limiting the opportunities for interaction and affective involvement that are a part of learning and sexual discovery and making living with this disease harder. Many of these teenagers do not have the capacity to respond to the demands of their environment or own will of independence. Among the teenagers evaluated, we discovered that a majority had been in school for a significant period. Nevertheless, they had a significant deficiency in learning, with only $10 \%$ being able to read and write correctly.

Concerning the future perspectives of the teenagers, practically one-third intended to work, most wanted to get married and have children, demonstrating life projects, despite the great dependence they face today. On the other hand, two-thirds did not perform any activity outside their homes, confirming great dependence. We should emphasize that not all mentally challenged individuals are similar in their learning capacity and independence, emotional stability, and social abilities, yet most are capable of learning and developing some social abilities. Patients with DS with severe deficiency generally have difficulty with hygiene and self-care. Behaviortraining programs, such as intimate hygiene methods for the girls have good results in teenagers with mild or moderate deficiencies. Siemaszko et al (7) in studying the menstrual history of teenagers with DS found that only $44 \%$ were autonomous as to menstrual hygiene, $44 \%$ needed some type of help, and $12 \%$ were totally dependent.

During puberty, such teenagers are faced with an ever changing physique, and for them, body image is very important because they make themselves attractive, desired, and normal. Teenagers with DS frequently have unique features, which may be a risk factor for the development of difficulties in social adaptation and is even harder when living in a society that gives such importance to body image. Merrick et al (5) found a mean age of 12.5 years for first menstruation; regular flow in the majority, which was also found in the present study. Goldstein (8) and Siemaszko (7) did not find differences in studying the menstrual histories of teenagers with DS, whereas Evans (9) found the age of first menstruation to be 13 months later in patients with DS.

Teenagers with DS present an ample variety of manifestations in relation to sexuality and reproductive health, depending on pubertal development, on their experiences and familial and social circumstances. When evaluating the interests of teenagers with DS in the exercise of sexuality, over half of the adolescents demonstrated interest in the opposite sex. That $18 \%$ of the respondents know what masturbation is, with $42 \%$ masturbating frequently and $24 \%$ of these masturbating on a daily basis, is compatible with findings by Pueschel and Scola (6). Another consequence of social isolation for these teenagers is that they receive less information regarding sexuality, reproduction and conception. Parents, teachers, and doctors do not feel comfortable discussing this theme, which impedes the patients from having adequate sexual education. Castelao et al (10) evaluated patients with DS and the health team that cared for them and discovered that the parents saw their offspring as eternal children and were afraid that they might assume a sexual life because of the risks.

Health professionals are also not prepared for the orientation of the exercise of sexuality in such adolescents. In our study, $34 \%$ of teenagers received education about sexuality, and the majority $(70 \%)$ 
received such education from their parents. Yet, only $18 \%$ had discussed sex with their parents and the same percentage discussed sex in school. Parents should be educated in relation to the existing taboos, so that in an integrated fashion and without contradiction, they can work with their children about sexual issues in a comfortable manner. Parents must actively participate in the process, providing the space to expose their doubts and ask questions (11).

All these issues indicate the necessity for sexual education for patients with mental deficiencies, and the objective should be not only the use of condoms or birth-control pills but also the actions and attitudes of these teenagers, evaluating the particular limitations of each (12). Teenagers with DS, like other adolescents, have to express their feelings in an appropriate manner. Sexual repression can alter their internal equilibrium, lowering the possibility of psychological well-being. When well discussed, sexuality improves affective development, facilitating relationships, improving self-esteem, and integration within society. The information should always be repeated and have long-term attendance to guarantee the success of this learning process. Whenever possible, dramatization and audio-visual material should be stimulated.

Thus, for their greater social inclusion, such patients should undergo early interventions by multidisciplinary teams, so that their development and social interaction are the best possible.

\section{CONCLUSIONS}

Teenagers with DS:

- Have normal feelings of sexuality

- Have significant difficulties in their autonomy and difficulties in school, needing careful interventions to make their social interaction the best possible
- Have normal pubertal development

- Are satisfied with their body image

- Have future perspectives of working, finding a partner and living a normal life of getting married and having children.

\section{ACKNOWLEDGMENTS}

We are grateful to the Support Center for Scientific Publications of Santa Casa de São Paulo, Faculty of Medical Sciences for the editorial assistance.

\section{REFERENCES}

1. Masters WH, Johnson VE, Kolodny R. Sexuality in mentally retarded adolescents. In: Kolodny $\mathrm{R}$, Johnson VE, Masters WH. Masters and Johnson on sex and human loving. Boston: Little Brown, 1988:500-51.

2. Gejer.D. Sexualidade e Anticoncepção no Adolescente Deficiente Mental. In: Crespin J, Reato LFN. HebiatriaMedicina da Adolescência. São Paulo: Roca, 2007:457-62.

3. Elkins TE, Haefner HK. Sexually related health care for developmentally disabled adolescents. Adolesc Med State Art Rev 1992;3:331-8.

4. Blum RW. Sexual health contraceptive needs of adolescents with chronic conditions. Arch Pediatr Adolesc Med 1997; 151:290-7.

5. Merrick J, Kandel I, Vardi G. Adolescents with Down Syndrome. Int J Adolesc Med Health 2004;16(1):13-9.

6. Pueschel SM, Scola PS. Parent's perception of social and sexual functions in adolescents with Down syndrome. J Ment Defic Res 1988;32: 215-20.

7. Siemasko K, et al. Menarche, menstrual cycles and menstrual hygiene in adolescents with Down syndrome. Rev Soc Argent Ginecol Infanto Juvenil 1998;5 (2):57-63. 
8. Goldstein H. Menarche, menstruation, sexual relations and contraception of adolescent females with Down syndrome. Eur J Obstet Gynnecol Reprod Biol 1988;27(4):343-9.

9. Evans AL, McKinlay IA. Sexual maturation in girls with severe mental handicap. Child Care Health Dev 1988; 14(1):59-69.

10. Castelao TB, Schiavo MR, Jurberg P. Sexuality in Down syndrome individuals. Rev Saude Publica 2003;37(1):32-9.

11. Daquinta R. Programa de educación sexual "Venga la Esperanza"; Sexual Education Program: Mediciego 2004.

12. Eastgate G. Sex, consent and intellectual disability. Aust Fam Physician 2005;34 (3):163-6. 